\title{
Association of Pigment Epithelium Derived Factor With von Willebrand Factor and Plasminogen Activator Inhibitor 1 in Patients With Type 2 Diabetes
}

\author{
D. KARASEK ${ }^{1}$, J. SPURNA ${ }^{1}$, V. KUBICKOVA ${ }^{2}$, O. KRYSTYNIK ${ }^{1}$, L. CIBICKOVA ${ }^{1}$, \\ J. SCHOVANEK ${ }^{1}$, D. GOLDMANNOVA ${ }^{1}$
}

${ }^{1}$ Third Department of Internal Medicine - Nephrology, Rheumatology and Endocrinology, Faculty of Medicine and Dentistry, University Hospital and Palacky University, Olomouc, Czech Republic, ${ }^{2}$ Department of Clinical Biochemistry, University Hospital, Olomouc, Czech Republic

Received September 5, 2018

Accepted December 17, 2018

Epub Ahead of Print March 22, 2019

\section{Summary}

To compare circulating pigment epithelium derived factor (PEDF) levels in type 2 diabetes patients (T2D) with and without metabolic syndrome (MetS+/-) to healthy controls and assess PEDF association with plasminogen activator inhibitor-1 (PAI-1) and von Willebrand factor (VWF) as markers of endothelial dysfunction. Fifty T2D individuals and forty healthy controls were included. PEDF, PAI-1, vWF, anthropological parameters, lipids, and markers of insulin resistance were investigated in all subjects. Compared to controls only MetS+ diabetics had higher PEDF levels $[14.2(10.2-16.0) \mathrm{mg} / \mathrm{l}$ vs. 11.1 (8.6-14.4) mg/l; $\mathrm{p}<0.05]$. PEDF significantly correlated: positively with body mass index $(\rho=0.25)$, smoking $(\rho=0.21)$, C-reactive protein $(\rho=0.22)$, triglycerides $\quad(\rho=0.38)$, non-HDL-cholesterol $\quad(\rho=0.39)$, apolipoprotein B $(\rho=0.38)$, fasting glucose $(\rho=0.22)$, glycated hemoglobin $(\rho=0.24)$, C-peptide $(\rho=0.28)$, insulin $(\rho=0.26)$; and negatively with $\mathrm{HDL}$-cholesterol $(\rho=-0.42)$ and apolipoprotein $\mathrm{A} 1$ $(\rho=-0.27)$. Independent association of PEDF with vWF in T2DMetS- subjects was found. Significantly elevated PEDF in T2DMet+ patients and its association with adverse metabolic profile confirmed PEDF as a marker of insulin resistance. Negative independent association of PEDF with vWF in T2DMetSpatients may reveal its angio-protective role.

\section{Key words}

Pigment epithelium derived factor • von Willebrand factor • Plasminogen activator inhibitor-1 • Diabetes • Metabolic syndrome

\section{Corresponding author}

D. Karasek, Third Department of Internal Medicine - Nephrology, Rheumatology and Endocrinology, University Hospital Olomouc, I.P. Pavlova 6, 77900 Olomouc, Czech Republic. E-mail: david.karasek@fnol.cz

\section{Introduction}

Pigment epithelium derived factor (PEDF) belongs to the most abundantly secreted adipokines, its circulating levels in plasma are comparable with adiponectin concentrations (Famulla et al. 2011). It was first identified as a neurotrophic factor produced by the human retinal pigment epithelial cells (Tombran-Tink et al. 1991). Later, its angio-inhibitory affects by regulating the vascular endothelial growth factor receptor 1 proteolysis was found (Cai et al. 2006, Yamagishi et al. 2018). These properties made it a promising candidate for treatment of diabetic retinopathy and neuropathy (Yamagishi et al. 2018, Elahy et al. 2014). The role of PEDF in diabetic cardiovascular $(\mathrm{CV})$ changes is rather controversial. Firstly, it has been suggested to have a protective effect in atherogenesis because of its anti-inflammatory, anti-oxidant and anti-thrombotic properties in the arterial walls and platelets. Due to these anti-atherothrombotic activities, some authors even suggested PEDF substitution as a novel therapeutic strategy for atherothrombosis (Rychli et al. 2009, Yamagishi et al. 2010). Although these observations 
suggest that PEDF could play a protective role against cardiovascular (CV) disease by acting as an inhibitor of plaque angiogenesis, its therapeutic application should be with caution because PEDF may suppress endothelium repair within the atherosclerotic lesions or collateral formation following myocardial ischemia (Yamagishi et al. 2018). However, PEDF inhibited growth, migration and proliferation of smooth muscle cells and its administration suppressed oxidative stress generation and apoptotic cell death around the infarcted areas, which was associated with attenuated myocardial fibrosis in non-infarcted areas. Further, PEDF treatment improved left ventricular ejection fraction, ameliorated diastolic dysfunction, and inhibited the increase in left ventricular mass index after myocardial infarction in rats (Ueda et al. 2011, Zhang et al. 2015).

Circulating levels of PEDF are elevated in various metabolic disorders, such as type 2 diabetes mellitus (T2D), obesity, metabolic syndrome (MetS) and polycystic ovarian syndrome, and positively correlate with cardio-metabolic risk factors and markers of insulin resistance (Famulla et al. 2011, Yamagishi et al. 2018). Impaired fatty acid oxidation and glucose uptake, increased synthesis of inflammatory mediators, mitochondrial dysfunction, enhanced lipolysis and ectopic lipid deposition have been suggested as potential PEDF-mediated mechanisms leading to the development of insulin resistance (Carnagarin et al. 2015, Crowe et al. 2009). On the contrary, compared with control mice, PEDF-deficient mice were obese and insulin resistant and intraperitoneal injection of PEDF for 4 weeks improved fasting hyperglycemia and ameliorated impaired hepatic insulin signaling pathways in PEDF-knockout mice (Gattu et al. 2014). These observations suggest that PEDF might improve the metabolic derangements and insulin resistance partly by suppressing oxidative stress generation and/or inflammatory reactions in the adipose tissue and liver (Yamagishi et al. 2018). PEDF may also ameliorate insulin resistance by restoring the decreased level of adiponectin partly via blockade of the deleterious effects of advanced glycation end products (AGEs) on adipocytes (Maeda et al. 2011). Therefore, effects of PEDF on insulin resistance, glucose tolerance, and adiposity may differ, depending on cell type and culture conditions, animal species, and experimental models (Yamagishi et al. 2018, Lakeland et al. 2014).

Diabetes mellitus is a major risk factor for $\mathrm{CV}$ diseases, which are the most common cause of death among adults with diabetes. The metabolic syndrome
(MetS) is associated with a 2-fold increase in risk for CV diseases and CV mortality (Mottillo et al. 2010). Visceral obesity, hypertension and dyslipidemia - the other components of MetS - dramatically increase CV risk in patients with diabetes. Data from the Third National Health and Nutrition Examination Survey (NHANES III) in adults aged 50 years or older indicated that the prevalence of coronary heart disease (CHD) was greatest in individuals with MetS and diabetes. CHD prevalence was $19.2 \%$ in individuals with both MetS and diabetes, $13.9 \%$ in those with MetS but not diabetes, and only $7.5 \%$ in those with diabetes but not MetS (Ginsberg et al. 2009). Patients with the MetS (Coffey et al. 2011, Mertens et al. 2006, Wei et al. 2013) and T2D (Yarmolinsky et al. 2016) have higher levels of plasminogen activator inhibitor-1 (PAI-1), a factor known to increase the risk of cardiovascular disease. Some authors also found higher levels of von Willebrand factor (vWF) in subjects with the MetS (Wei et al. 2013, Lim et al. 2004) or T2D (Chen et al. 1995), especially in patients with diabetic nephropathy (Hirano et al. 2000, Parving et al. 1996). Whereas serum vWF levels were not elevated in diabetic patients without diabetic nephropathy (Hirano et al. 2000, Parving et al. 1996), patients with prediabetes (Genc et al. 2012), or dyslipidemic subjects without atherosclerosis manifestation (Karasek et al. 2011). A little is known about relation between PEDF and PAI-1, there is no information about PEDF may act through vWF influence.

Based on these facts we could hypothesize, that circulating PEDF levels should be higher in patients with T2D and they may be related to mentioned prothrombotic markers. The aim of this study was to compare circulating levels of PEDF in T2D patients (with and without MetS) to healthy controls; especially we focused on association between PEDF and PAI-1 or vWF in these subjects.

\section{Methods}

The study was undertaken as a cross-sectional study with T2D patients and healthy controls in accordance with the principles of the Declaration of Helsinki as revised in 2008. It was reviewed and approved by Ethics Committee of Medical Faculty and University Hospital Olomouc and informed consent was obtained from all participants. They were asked about their previous medical history, especially cardiovascular status, medication, diabetic complications, and duration. 
Body mass index (BMI), waist circumference, systolic and diastolic blood pressure (SBP and DBP), complete physical examination, and laboratory tests were also performed. Exclusion criteria were as follows: type 1 diabetes, secondary or genetic type of diabetes, anticoagulant therapy, acute infection, or trauma. Diabetes was defined as fasting plasma glucose $\geq 7 \mathrm{mmol} / 1$ or using of peroral antidiabetic drugs (PADs) and/or insulin.

\section{Subjects}

Fifty individuals with T2D ( 23 men, 27 women; age $=51.3 \pm 11.7)$ and 40 healthy controls $(15 \mathrm{men}$, 25 women; age $=48.8 \pm 9.5$ ) with no medication were included into the study. All patients with diabetes were treated by insulin and/or PADs. Insulin was administered in $77 \%$ of them, $96 \%$ were treated by PADs. The most commonly used PAD was metformin (86\%), then incretins (glucagon-like peptide 1 receptor agonists or dipeptidyl peptidase-4 inhibitors - 36\%), gliflozins (16\%), and sulfonylurea's (6\%). $66 \%$ percent T2D subjects were treated by hypolipidemic drugs and $82 \%$ by antihypertensive therapy. There were $20 \%$ smokers in the T2D group and $15 \%$ in the control group. Diabetics were divided into two groups: with (T2D MetS+: $n=30$; 11 men, 19 women; age $=49.5 \pm 9.1$ ) and without (T2D MetS-: $\mathrm{n}=20 ; 12$ men, 8 women; age $=53.8 \pm 14.5$ ) MetS. A diagnosis of MetS was based on harmonized definition (Alberti et al. 2009) with values for waist circumference suggested by Adult Treatment Panel III. The presence of any three of five risk factors constituted a diagnosis of MetS: 1) waist circumference $>102 \mathrm{~cm}$ in men or $>88 \mathrm{~cm}$ in women; 2) triglycerides (TG) levels $\geq 1.7 \mathrm{mmol} / 1$ (or drug treatment for elevated $\mathrm{TG}$ ); 3) high density lipoprotein cholesterol (HDL-C) levels $<1.0 \mathrm{mmol} / 1$ in men or $<1.3 \mathrm{mmol} / 1$ in women (or drug treatment for decreased HDL-C); 4) SBP $\geq 130$ and/or DBP $\geq 85 \mathrm{~mm} \mathrm{Hg}$ (or specific antihypertensive treatment); 5) and fasting glucose $\geq 5.6 \mathrm{mmol} / 1$ (or specific antidiabetic treatment).

\section{Laboratory analyses}

Venous blood samples were drawn in the morning after a 12 -h fast. For assessment of hemostatic markers, venous blood was collected into $3.8 \%$ sodium citrate tubes and plasma was obtained after centrifugation. Routine serum biochemical parameters (levels of cholesterol, TG, apolipoproteins, glucose, glycated hemoglobin, C-reactive protein) were analyzed on Cobas 8000 (Roche, Mannheim, Germany) on the day of blood collection. Concentrations of PEDF were measured in the sample aliquots stored at $-80{ }^{\circ} \mathrm{C}$, no longer than 6 months. Other special analytes (insulin, C-peptide, PAI-1, vWF) were stored at $-20^{\circ} \mathrm{C}$, no longer than 1 month.

Total cholesterol (TC), TG and HDL-C were determined enzymatically on Cobas 8000 system (Roche, Mannheim, Germany). Determination of HDL-C was realized by a direct method without precipitation of apolipoprotein B (apoB) containing lipoproteins. Low density lipoprotein cholesterol (LDL-C) was calculated using Friedewald formula (LDL-C $=\mathrm{TC}-\mathrm{TG}^{*} 0.4537$ HDL-C for $\mathrm{TG}<4.5 \mathrm{mmol} / \mathrm{l})$. Non-HDL-cholesterol was calculated as follows: non-HDL-C $=$ TC - HDL-C. Glucose was determined using hexokinase method (Roche, Basel, Switzerland). Concentration of apoB and apolipoprotein A1 (apoA1) was determined immunoturbidimetrically on Cobas 8000 analyzer (TinaQuant Apo A1, TinaQuant Apo B kits, all Roche, Mannheim, Germany). Glycated hemoglobin levels $\left(\mathrm{HbA}_{1 \mathrm{C}}\right)$ were measured by ion exchange chromatography using Arkray Adams HA-8180V analyzer (Arkray Corporation, Kyoto, Japan). High sensitive C-reactive protein (hs-CRP) was assessed by means of an ultra-sensitive latex immunoturbidimetric method (CRP latex TinaQuant kit; Roche). Insulin and C-peptide were determined by the commercially available kits (Immunotech, Marseille, France) using specific antibodies by the IRMA methods.

Von Willebrand factor (immunoturbidimetric assay Instrumentation Laboratory Spa, Milan, Italy) and plasminogen activator inhibitor-1 (ELISA, Technoclone, Vienna, Austria) were examined from human plasma. Pigment epithelium derived factor was assessed by PEDF Human ELISA kit (Biovendor Laboratory Medicine Inc., Brno, Czech Republic), according to the manufacturer's instructions. There are more details for this kit: assay sensitivity: $0.045 \mathrm{ng} / \mathrm{ml}$; specificity: antibodies used in this ELISA kit are specific for human PEDF; cross-reactivity mammalian serum sample: yes for cat, and monkey, no for bovine, dog, goat, hamster, horse, mouse, pig, rabbit, rat, and sheep; intra-assay precision: CV $3.73 \%$ (mean $6.61 \mu \mathrm{g} / \mathrm{ml}$ ); inter-assay precision: CV $5.9 \%$ (mean $3.32 \mu \mathrm{g} / \mathrm{ml})$.

\section{Statistical analysis}

All values were expressed as means \pm standard deviation (SD), or as median $\left(1^{\text {st }}-3^{\text {rd }}\right.$ quartile of values) for parameters with non-normal distribution according to 
the Shapiro-Wilk's test. Fisher exact test for categorical variables and t-test for continuous variables were used. Differences in variables between the groups were analyzed with ANOVA after the adjustment for age. Spearman correlation analyses tested univariate correlations between parameters in all groups. Multivariate regression analyses were used for testing for an independent association between dependent and independent variables. Non-normally distributed variables were logarithmically transformed before analyses. Probability values of $\mathrm{p}<0.05$ were considered as statistically significant.

\section{Results}

Basic characteristics, endothelial hemostatic markers (Table 1)

Compared to healthy controls T2D patients were obese. Higher waist circumference was detected even in diabetics without MetS. Probably, due to antihypertensive therapy (in $82 \%$ of $\mathrm{T} 2 \mathrm{D}$ patients) there were no differences in SBP or DBP within the groups. Although $66 \%$ of diabetics were treated by hypolipidemic drugs, subjects with MetS still showed signs of atherogenic dyslipidemia (lower HDL-C and apoA1, higher TG and apoB). Levels of $\mathrm{HbA}_{1 \mathrm{C}}$, insulin and C-peptide were of course higher in T2D patients. There were no statistical differences in diabetes duration (6.9 \pm 6.5 vs. $7.2 \pm 6.2$ years - n.s.), in antidiabetic treatment (insulin $77 \%$ vs. $80 \%$ - n.s., metformin $90 \%$ vs. $80 \%$ - n.s., incretins $40 \%$ vs. $30 \%$ - n.s., gliflozins $20 \%$ vs. $13 \%-$ n.s., and sulfonylurea's $10 \%$ vs. $3 \%-$ n.s.), in microvascular (53\% vs. $55 \%$ - n.s.) or macrovascular (13\% vs. $10 \%$ - n.s.) complications between MetS+ and MetS- groups.

Pigment epithelium derived factor, its relationship to assessed parameters

Figure 1 shows circulating PEDF levels in individual groups. Only T2D patients with MetS had higher PEDF compared to healthy controls [14.2 (10.216.0) $\mathrm{mg} / \mathrm{l}$ vs. 11.1 (8.6-14.4) $\mathrm{mg} / \mathrm{l} ; \mathrm{p}<0.05]$, whereas PEDF levels in diabetics without MetS did not differ

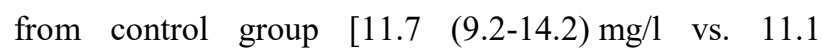
(8.6-14.4) mg/l; n.s.]. In all subjects PEDF significantly $(p<0.05)$ correlated: positively with BMI $(\rho=0.25)$, smoking $(\rho=0.21)$, hs-CRP $(\rho=0.22)$, TG $(\rho=0.38)$, non-HDL-C $(\rho=0.39)$, apoB $(\rho=0.38)$, fasting glucose $(\rho=0.22)$, glycated hemoglobin $(\rho=0.24)$, C-peptide $(\rho=0.28)$ and insulin $(\rho=0.26)$; negatively with HDL-C $(\rho=-0.42)$ and apoA1 $(\rho=-0.27)$. In T2D patients with MetS PEDF correlated positively only with non-HDL-C $(\rho=0.39)$, and negatively with HDL-C $(\rho=-0.54)$, whereas in subjects without MetS there were positive correlations with smoking $(\rho=0.43)$, C-peptide $(\rho=0.50)$ and a negative correlation of PEDF with $\operatorname{vWF}(\rho=-0.46)$. Significant correlations of PEDF with PAI-1 were not observed. In multiple linear regression analysis of factors significantly correlated with $\mathrm{vWF}$ in T2DMetS- group (age: $\rho=0.55$, BMI: $\rho=0.57$, DBP: $\rho=-0.48$, smoking: $\rho=0.46$, and PEDF: $\rho=-0.46$ ) vWF was independently associated with PEDF (Table 2).

\section{Discussion}

Among T2D patients only individuals with MetS had significantly higher circulating levels of PEDF. They were associated with adverse metabolic profile, especially with signs of atherogenic dyslipidemia, worse glycemic compensation, hyperinsulinemia, obesity, chronic inflammation and smoking. Only in the group of T2D subjects without MetS a significant correlation between PEDF and vWF levels was found. They were independently associated with PEDF. Statistically significant association between PEDF and PAI-1 was not observed in any group of study participants.

Increased circulating PEDF levels in subjects with MetS and their association with adverse metabolic profile have been already observed (Yamagishi et al. 2018). Yamagishi et al. (2006) also found that serum PEDF levels adjusted for age-, sex-, and uric acid were increased in proportion to the number of MetS components. Many researchers have reported the positive correlation between PEDF and cardiometabolic risk factors, such as waist-to-hip ratio, waist circumference, homeostasis model of assessment of insulin resistance (HOMA), TG, and reduced HDL-C levels in patients with obesity, MetS or T2D (Yamagishi et al. 2018). In patients with impaired fasting glucose or T2D, PEDF concentrations were associated with HOMA, BMI, and decreased HDL-C, and after niacin therapy, HDL-C levels were an independent determinant of PEDF in these patients (Pek et al. 2013). Furthermore, waist circumference, TG, creatinine, and tumor necrosis factor- $\alpha$ (TNF- $\alpha)$ were independently correlated with PEDF in T2D patients (Nakamura et al. 2009). Longitudinal changes in circulating PEDF levels during the 1-year observational periods were positively 
associated with BMI. Therefore, serum PEDF levels may represent a biomarker of insulin resistance and/or visceral obesity in humans, although the pathophysiological role of PEDF in insulin resistance is rather controversial (Yamagishi et al. 2018).

Table 1. Basic clinical and laboratory characteristics, endothelial hemostatic markers in individual groups.

\begin{tabular}{|c|c|c|c|c|}
\hline & $\begin{array}{l}\text { T2D group } \\
(n=50)\end{array}$ & $\begin{array}{c}\text { T2D MetS }{ }^{+} \text {group } \\
(\mathbf{n}=\mathbf{3 0})\end{array}$ & $\begin{array}{l}\text { T2D } \text { MetS }^{-} \text {group } \\
(\mathbf{n = 2 0})\end{array}$ & $\begin{array}{l}\text { Healthy controls } \\
\qquad(n=40)\end{array}$ \\
\hline Age (years) & $51.3 \pm 11.7^{*}$ & $49.5 \pm 11.9$ & $53.7 \pm 14.5^{*}$ & $48.8 \pm 9.5$ \\
\hline Men/Women & $23 / 27$ & $11 / 19$ & $12 / 8$ & $15 / 25$ \\
\hline$B M I\left(\mathrm{~kg} / \mathrm{m}^{2}\right)$ & $30.6(26.7-36.1)^{* * *}$ & $35.6(31.2-37.5)^{* * *}$ & $26.4(24.9-29.4)^{*}$ & $23.0(21.1-25.9)$ \\
\hline Waist (cm) & $103.0(98.1-118.8)^{* * *}$ & $119.0(110.5-123.3)^{* * *}$ & $99.1(95.0-101.4)^{* * *}$ & $78.2(72.3-87.9)$ \\
\hline$S B P(m m ~ H g)$ & $129.5 \pm 15.4$ & $128.9 \pm 13.7$ & $130.5 \pm 17.8$ & $125.0 \pm 12.9$ \\
\hline$D B P(m m ~ H g)$ & $80.9 \pm 8.7 *$ & $80.1 \pm 7.6$ & $82.0 \pm 10.7^{*}$ & $76.9 \pm 9.1$ \\
\hline$T C(\mathrm{mmol} / \mathrm{l})$ & $4.8 \pm 1.4$ & $5.0 \pm 1.7$ & $4.6 \pm 0.9^{*}$ & $5.0 \pm 0.8$ \\
\hline$L D L-C(\mathrm{mmol} / \mathrm{l})$ & $2.5 \pm 0.8$ & $2.7 \pm 0.7$ & $2.2 \pm 0.9 *$ & $2.7 \pm 0.9$ \\
\hline$H D L-C(\mathrm{mmol} / \mathrm{l})$ & $1.2 \pm 0.4 * * *$ & $1.0 \pm 0.3 * * *$ & $1.5 \pm 0.3^{*}$ & $1.8 \pm 0.6$ \\
\hline non-HDL-C (mmol/l) & $3.6 \pm 1.5$ & $4.0 \pm 1.8$ & $3.1 \pm 0.9$ & $3.2 \pm 1.1$ \\
\hline$T G(\mathrm{mmol} / \mathrm{l})$ & $1.8(1.3-2.3)^{*}$ & $2.3(1.8-3.0)^{*}$ & $1.1(0.9-1.7)$ & $0.9(0.7-1.3)$ \\
\hline$A p o B(g / l)$ & $1.0 \pm 0.3$ & $1.1 \pm 0.2$ & $0.9 \pm 0.2$ & $0.9 \pm 0.2$ \\
\hline ApoAl $(\mathrm{g} / \mathrm{l})$ & $1.4 \pm 0.3 * * *$ & $1.3 \pm 0.2 * * *$ & $1.6 \pm 0.2$ & $1.8 \pm 0.4$ \\
\hline$H b A_{l c}(\mathrm{mmol} / \mathrm{mol})$ & $61.0(45.5-76.5)^{* * *}$ & $58.5(47.8-83.2)^{* * *}$ & $62.0(42.9-71.8) * * *$ & $32.0(29.7-34.5)$ \\
\hline Insulin $(m I U / l)$ & $21.1(12.1-42.3)^{* * *}$ & $20.8(13.0-43.1)^{* * *}$ & $21.9(8.1-31.6)^{* * *}$ & $6.1(4.4-6.9)$ \\
\hline C-peptide (pmol/l) & $780.0(605.4-1,047.8)^{* * *}$ & $790.1(615.0-974.0)^{* * *}$ & $765.6(591.0-1,098.6)^{* * *}$ & $452.5(348.0-590.8)$ \\
\hline$h s-C R P(m g / l)$ & $3.1(1.3-5.3)^{* * *}$ & $4.9(2.9-10.4)^{* * *}$ & $1.2(0.6-2.5)$ & $1.1(0.6-2.5)$ \\
\hline$P A I-1(\mu g / l)$ & $80.9(56.3-117.6)^{* * *}$ & $86.4(68.0-125.7)^{* * *}$ & $60.7(21.9-103.4)^{*}$ & $39.0(29.1-57.4)$ \\
\hline$v W F(\%)$ & $170.5(107.7-195.0)^{*}$ & $185.0(107.1-202.6)^{*}$ & $158.4(135.2-186.4)$ & $118.0(93.4-166.0)$ \\
\hline
\end{tabular}

$\mathrm{T} 2 \mathrm{D}=$ all type 2 diabetes individuals; T2DMetS $+=\mathrm{T} 2 \mathrm{D}$ individuals with metabolic syndrome; T2DMetS- $=\mathrm{T} 2 \mathrm{D}$ individuals without metabolic syndrome; $\mathrm{BMI}=$ body mass index; $\mathrm{SBP}=$ systolic blood pressure; $\mathrm{DBP}=$ diastolic blood pressure; $\mathrm{TC}=$ total cholesterol; $\mathrm{LDL}-\mathrm{C}=\mathrm{LDL}$ cholesterol; $\mathrm{HDL}-\mathrm{C}=\mathrm{HDL}$ cholesterol; non-HDL-C=non-HDL cholesterol; $\mathrm{TG}=$ triglycerides; apoB=apolipoprotein $\mathrm{B}$; apoA1=apolipoprotein $\mathrm{A} 1 ; \mathrm{HbA}_{1 c}=$ glycated hemoglobin $\mathrm{A}_{1 \mathrm{c}}$; hs-CRP=high sensitive C-reactive protein; PAI-1=plasminogen activator inhibitor-1, vWF=von Willebrand factor. Values are expressed as median (25 and 75 percentile). $* p<0.05, * * p<0.01, * * * p<0.001$, that means levels of statistical significant differences between T2D and control groups according to ANOVA (after adjustment for age), t-test (for age only) or Fischer exact test (for sex only).

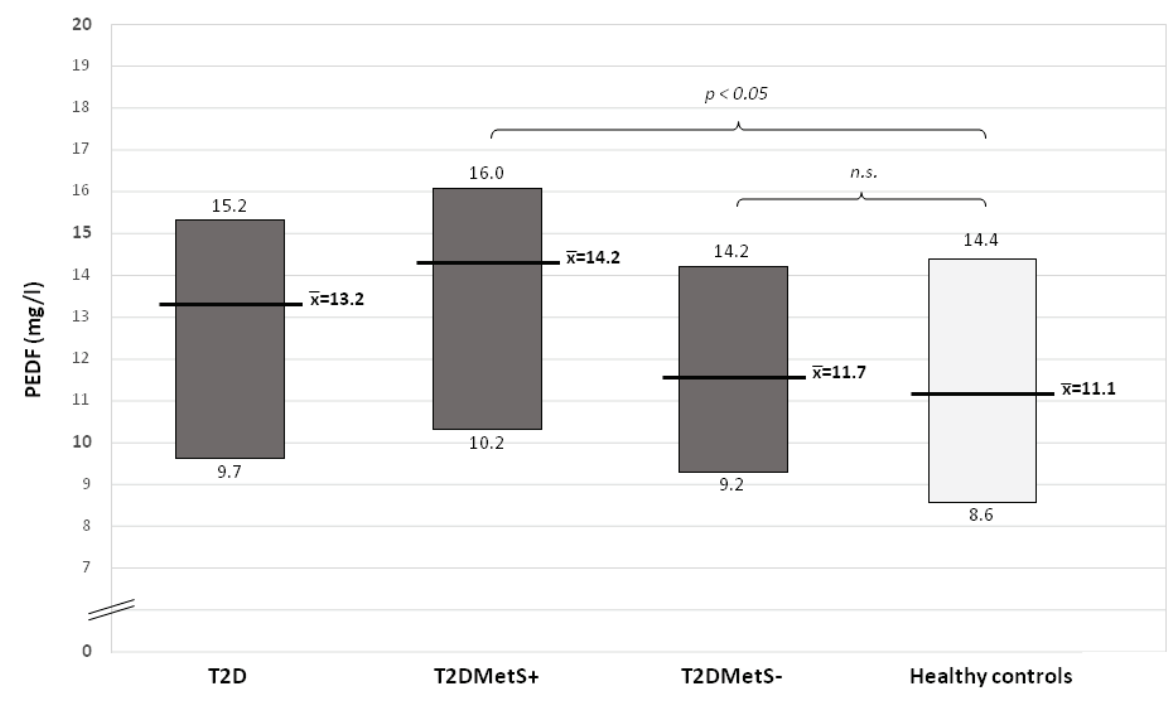

Fig. 1. Levels of pigment epithelium derived factor in individual groups. T2D=all type 2 diabetes individuals; $\mathrm{T}^{2} \mathrm{DMetS}^{+}=$ T2D individuals with metabolic syndrome; $\mathrm{T}^{2 \mathrm{DMet}} \mathrm{S}^{-}=\mathrm{T} 2 \mathrm{D}$ individuals without metabolic syndrome; values are expressed as median and interquartile range. 
Table 2. Multiple linear regression analysis of independent factors affecting von Willebrand factor in T2DMetS- group, $R^{2}=0.973$.

\begin{tabular}{lccc}
\hline & Regression coefficient & Standard error & p-value \\
\hline Age & $\mathbf{0 . 4 3 1}$ & $\mathbf{0 . 1 6 8}$ & $\mathbf{0 . 0 2 1}$ \\
BMI & $\mathbf{5 . 0 9 0}$ & $\mathbf{1 . 0 2 1}$ & $<\mathbf{0 . 0 0 1}$ \\
DBP & -0.307 & 0.361 & 0.407 \\
smoking & 0.028 & 0.067 & 0.677 \\
PEDF & $\mathbf{- 4 . 2 6 5}$ & $\mathbf{1 . 0 6 6}$ & $\mathbf{0 . 0 0 1}$ \\
\hline
\end{tabular}

T2DMet $S^{-}=$type 2 diabetes individuals without metabolic syndrome; BMI=body mass index; DBP=diastolic blood pressure; $\mathrm{PEDF}=$ pigment endothelium derived factor.

There is some controversy about PEDF in vascular involvement too. In two cross-sectional studies independent positive associations of PEDF with subclinical markers of atherosclerosis (carotid and/or brachial intima-media thickness) (Tahara et al. 2011, Kajikawa et al. 2016), and with vascular inflammation within the atherosclerotic plaques (Tahara et al. 2011), and a negative association with nitroglycerin-induced vasodilation were found (Kajikawa et al. 2016). Authors suggest that PEDF may be a factor directly associated with atherosclerosis or may be at least a new biochemical marker of atherosclerosis (Tahara et al. 2011, Kajikawa et al. 2016). However, due to cross-sectional design of these studies there are questions of whether elevation of PEDF was a cause or consequence of impaired vascular function, inflammation and atherosclerosis and whether PEDF levels are not elevated as a compensatory countersystem to attenuate the inflammation and atherosclerosis. Liu et al. (2014) reported that plasma levels of PEDF were decreased in patients with acute coronary syndrome relative to control subjects, and lower PEDF values could predict future adverse $\mathrm{CV}$ events in these patients. Recently Li et al. (2018) observed significantly lower PEDF levels in CHD patients than in healthy subjects and a negative correlation between PEDF levels and severity of CHD in Chinese population. There are many studies verifying athero- and cardio-protective properties of PEDF (Yamagishi et al. 2018).

On the contrary, there are only a few data on the impact of PEDF on endothelial hemostatic markers. PEDF administration is able to reduce PAI-1 activity and ADP-induced platelet aggregation in rats (Yamagishi et al. 2009) and to suppress PAI-1 gene expression in the rat diabetic kidneys (Ishibashi 2016). Thus, PEDF antihemostatic effects may be caused at least in part by suppressing PAI-1 and platelet aggregation (Yamagishi et al. 2018). If the same effect also applies to humans remains unclear. We did not confirm a significant association between PAI-1 and PEDF in our patients. However, both PEDF and PAI-1 were associated with the same metabolic parameters (BMI, CRP, insulin, C-peptide, fasting glucose, $\mathrm{HbA}_{1 \mathrm{C}}$ ) and atherogenic dyslipidemia (positively with $\mathrm{TG}$, apoB and negatively with HDL-C, and apoA1; not shown in results), which reflected their common origin in the fat tissue and a close relation to insulin resistance. Although in a large number of patients the insulin levels were affected by insulin treatment. Both PEDF and PAI-1 were also significantly reduced after weight loss in overweight postmenopausal women (Duggan 2016). Thus, weight reduction itself (and not the increase of circulating PEDF levels) led to PAI-1 levels decrease.

The negative correlation between PEDF and vWF in T2D patient without MetS was somewhat surprising. As we know, this association has not been studied and published yet. The negative independent association between vWF and PEDF in T2D may point out another anti-thrombotic action of PEDF. Von Willebrand factor is a large multimeric glycoprotein that mediates the attachment of platelets to damaged endothelium and also serves as the carrier protein for coagulation factor VIII, protecting it from proteolytic degradation. It is synthesized exclusively by endothelial cells and megakaryocytes. Elevated vWF levels reflect stimulation of the endothelial cells and in diabetic patients, vWF correlates with $\mathrm{CV}$ outcome and risk of chronic complications (Gragnano et al. 2017). On the contrary PEDF blocks endothelial cells proliferation and pathological angiogenesis, and some observations suggest that PEDF could play a protective role against $\mathrm{CV}$ disease by acting as an inhibitor of plaque angiogenesis (Yamagishi et al. 2018). Of course, we don't know, if PEDF may directly influence the vWF levels. However, there are many adipokines with positive or negative 
impact on endothelial function and/or on platelet activation and there are many different mediators (cytokines, superoxide anions, histamine, and thrombin) producing an increase in vWF levels through various mechanisms (Gragnano et al. 2017, Vilahur et al. 2017). We previously found positive independent association between $\mathrm{VWF}$ and serum adipocyte fatty acid binding protein (A-FABP) in dyslipidemic individuals (Karasek et al. 2012), subjects with MetS (Novotny et al. 2014) and in T2D patients (Spurná et al. 2018), in whose vWF levels also negatively correlated with adiponectin. Our data suggests that adipokines may potentially affect vWF production or its metabolism and by this way can modulate a prothrombotic state.

The limitations of this study are its crosssectional design and relatively high number of participants treated by drugs, that may influence endothelial function especially in subjects with MetS (93\% of T2D patients with MetS and $25 \%$ of T2D patients without MetS were treated by statins, $87 \%$ of T2D patients with MetS and $65 \%$ T2D patients without MetS were treated by ACE-inhibitors or sartans). Therefore, a larger prospective study is needed to verify the association of serum PEDF levels with prothrombotic endothelial makers. In addition, evaluation of the effects of interventions that increase circulating levels of PEDF on development of endothelial dysfunction to clarify the role of PEDF in initial stage of atherosclerosis should be drawn.

\section{Conclusions}

Significantly elevated circulating levels of PEDF in T2D patients with metabolic syndrome and its association with adverse metabolic profile confirmed this factor as a marker of insulin resistance and/or visceral obesity. Independent negative association of PEDF with von Willebrand factor in T2D patients without MetS may point out another mechanism of its angio-protective role. This finding must be verified by other prospective and interventional studies.

\section{Conflict of Interest}

There is no conflict of interest.

\section{Acknowledgements}

Supported by a grant IGA_LF_2018_010 and MH CZ DRO (FNO1, 00098892) - 87-62.

\section{References}

ALBERTI KG, ECKEL RH, GRUNDY SM, ZIMMET PZ, CLEEMAN JI, DONATO KA, FRUCHART JC, JAMES WP, LORIA CM, SMITH SC JR; INTERNATIONAL DIABETES FEDERATION TASK FORCE ON EPIDEMIOLOGY AND PREVENTION; NATIONAL HEART, LUNG, AND BLOOD INSTITUTE; AMERICAN HEART ASSOCIATION; WORLD HEART FEDERATION; INTERNATIONAL ATHEROSCLEROSIS SOCIETY; INTERNATIONAL ASSOCIATION FOR THE STUDY OF OBESITY: Harmonizing the metabolic syndrome: a joint interim statement of the International Diabetes Federation Task Force on Epidemiology and Prevention; National Heart, Lung, and Blood Institute; American Heart Association; World Heart Federation; International Atherosclerosis Society; and International Association for the Study of Obesity. Circulation 120: 1640-1645, 2009.

CAI J, JIANG WG, GRANT MB, BOULTON M: Pigment epithelium-derived factor inhibits angiogenesis via regulated intracellular proteolysis of vascular endothelial growth factor receptor 1 . J Biol Chem 281: 3604-3613, 2006.

CARNAGARIN R, DHARMARAJAN AM, DASS CR: PEDF-induced alteration of metabolism leading to insulin resistance. Mol Cell Endocrinol 401: 98-104, 2015.

CHEN JW, GALL MA, DECKERT M, JENSEN JS, PARVING HH: Increased serum concentration of von Willebrand factor in non-insulin dependent diabetic patients with and without diabetic nephropathy. BMJ 311: 1405-1406, 1995.

COFFEY CS, ASSELBERGS FW, HEBERT PR, HILlEGE HL, LI Q, MOORE JH, VAN GILST WH: The Association of the Metabolic Syndrome with PAI-1 and t-PA Levels. Cardiol Res Pract 2011: 541467, 2011.

CROWE S, WU LE, ECONOMOU C, TURPIN SM, MATZARIS M, HOEHN KL, HEVENER AL, JAMES DE, DUH EJ, WATT MJ: Pigment epithelium-derived factor contributes to insulin resistance in obesity. Cell Metab 10: 40-47, 2009. 
DUGGAN C, TAPSOBA JDE D, WANG CY, MCTIERNAN A: Dietary weight loss and exercise effects on serum biomarkers of angiogenesis in overweight postmenopausal women: a randomized controlled trial. Cancer Res 76: 4226-4235, 2016.

ELAHY M, BAINDUR-HUDSON S, CRUZAT VF, NEWSHOLME P, DASS CR: Mechanisms of PEDF-mediated protection against reactive oxygen species damage in diabetic retinopathy and neuropathy. J Endocrinol 222: R129-R139, 2014.

FAMULLA S, LAMERS D, HARTWIG S, PASSLACK W, HORRIGHS A, CRAMER A, LEHR S, SELL H, ECKEL J: Pigment epithelium-derived factor (PEDF) is one of the most abundant proteins secreted by human adipocytes and induces insulin resistance and inflammatory signaling in muscle and fat cells. Int J Obes (Lond) 35: 762-772, 2011.

GATTU AK, BIRKENFELD AL, IWAKIRI Y, JAY S, SALTZMAN M, DOLL J, PROTIVA P, SAMUEL VT, CRAWFORD SE, CHUNG C: Pigment epithelium-derived factor (PEDF) suppresses IL-1 $\beta$-mediated c-Jun N-terminal kinase (JNK) activation to improve hepatocyte insulin signaling. Endocrinology 155: 1373-1385, 2014.

GENC H, DOGRU T, TAPAN S, TASCI I, BOZOGLU E, GOK M, ASLAN F, CELEBI G, ERDEM G, AVCU F, URAL AU, SONMEZ A: Soluble CD40 ligand, soluble P-selectin and von Willebrand factor levels in subjects with prediabetes: the impact of metabolic syndrome. Clin Biochem 45: 92-95, 2012.

GINSBERG HN, MACCALLUM PR: The obesity, metabolic syndrome, and type 2 diabetes mellitus pandemic: Part I. Increased cardiovascular disease risk and the importance of atherogenic dyslipidemia in persons with the metabolic syndrome and type 2 diabetes mellitus. J Cardiometab Syndr 4: 113-119, 2009.

GRAGNANO F, SPERLONGANO S, GOLIA E, NATALE F, BIANCHI R, CRISCI M, FIMIANI F, PARIGGIANO I, DIANA V, CARBONE A, CESARO A, CONCILIO C, LIMONGELLI G, RUSSO M, CALABRÒ P: The role of von Willebrand factor in vascular inflammation: from pathogenesis to targeted therapy. Mediators Inflamm 2017: 5620314, 2017.

HIRANO T, OOKUBO K, KASHIWAZAKI K, TAJIMA H, YOSHINO G, ADACHI M: Vascular endothelial markers, von Willebrand factor and thrombomodulin index, are specifically elevated in type 2 diabetic patients with nephropathy: comparison of primary renal disease. Clin Chim Acta 299: 65-75, 2000.

ISHIBASHI Y, MATSUI T, TAIRA J, HIGASHIMOTO Y, YAMAGISHI S: Protective role of PEDF-derived synthetic peptide against experimental diabetic nephropathy. Horm Metab Res 48: 613-619, 2016.

KAJIKAWA M, MARUHASHI T, IWAMOTO Y, IWAMOTO A, ODA N, KISHIMOTO S, MATSUI S, AIBARA Y, HIDAKA T, KIHARA Y, CHAYAMA K, GOTO C, NOMA K, NAKASHIMA A, MATSUI T, YAMAGISHI SI, HIGASHI Y: Circulating level of pigment epithelium-derived factor is associated with vascular function and structure: A cross-sectional study. Int J Cardiol 225: 91-95, 2016.

KARASEK D, VAVERKOVA H, FRYSAK Z, ORSAG J, NOVOTNY D, HALENKA M, SLAVIK L: Relationship between serum adipocyte fatty acid-binding protein and endothelial/hemostatic markers in dyslipidemic subjects. Neuro Endocrinol Lett 33 (Suppl 2): 26-31, 2012.

KARASEK D, VAVERKOVA H, HALENKA M, JACKULIAKOVA D, FRYSAK Z, SLAVIK L, NOVOTNY D: Prothrombotic markers in asymptomatic dyslipidemic subjects. J Thromb Thrombolysis 31: 27-36, 2011.

LAKELAND TV, BORG ML, MATZARIS M, ABDELKADER A, EVANS RG, WATT MJ: Augmented expression and secretion of adipose-derived pigment epithelium-derived factor does not alter local angiogenesis or contribute to the development of systemic metabolic derangements. Am J Physiol Endocrinol Metab 306: E1367-E1377, 2014.

LI M, WANG S, ZHANG Y, MA S, ZHU P: Correlation between pigment epithelium-derived factor (PEDF) level and degree of coronary angiography and severity of coronary artery disease in a Chinese population. Med Sci Monit 24: 1751-1758, 2018.

LIM HS, LIP GY, BLANN AD: Plasma von Willebrand factor and the development of the metabolic syndrome in patients with hypertension. J Clin Endocrinol Metab 89: 5377-5381, 2004.

LIU J, WANG S, SHI J, GUO Y, LIU J, TAO T, ZHU P: The association study of plasma levels of pigment epitheliumderived factor with acute coronary syndrome in the Chinese Han population. Cardiology 127: 31-37, 2014. 
MAEDA S, MATSUI T, TAKEUCHI M, YAMAGISHI S: Pigment epithelium-derived factor PEDF) blocks advanced glycation end products (AGEs)-RAGE-induced suppression of adiponectin mRNA level in adipocytes by inhibiting NADPH oxidase-mediated oxidative stress generation. Int J Cardiol 152: 408-410, 2011.

MERTENS I, VERRIJKEN A, MICHIELS JJ, VAN DER PLANKEN M, RUIGE JB, VAN GAAL LF: Among inflammation and coagulation markers, PAI-1 is a true component of the metabolic syndrome. Int $J$ Obes (Lond) 30: 1308-1314, 2006.

MOTTILLO S, FILION KB, GENEST J, JOSEPH L, PILOTE L, POIRIER P, RINFRET S, SCHIFFRIN EL, EISENBERG MJ: The metabolic syndrome and cardiovascular risk a systematic review and meta-analysis. J Am Coll Cardiol 56: 1113-1132, 2010.

NAKAMURA K, YAMAGISHI S, ADACHI H, KURITA-NAKAMURA Y, MATSUI T, INOUE H: Serum levels of pigment epithelium-derived factor (PEDF) are positively associated with visceral adiposity in Japanese patients with type 2 diabetes. Diabetes Metab Res Rev 25: 52-56, 2009.

NOVOTNY D, VAVERKOVA H, KARASEK D, LUKES J, SLAVIK L, MALINA P, ORSAG J: Evaluation of total adiponectin, adipocyte fatty acid binding protein and fibroblast growth factor 21 levels in individuals with metabolic syndrome. Physiol Res 63: 219-228, 2014.

PARVING HH, NIELSEN FS, BANG LE, SMIDT UM, SVENDSEN TL, CHEN JW, GALL MA, ROSSING P: Macro-microangiopathy and endothelial dysfunction in NIDDM patients with and without diabetic nephropathy. Diabetologia 39: 1590-1597, 1996.

PEK S, TAVINTHARAN S, WOON K, NIYATI J, LIM SC, SUM CF: Associations between pigment epitheliumderived factor, insulin resistance and high density lipoprotein. Diabet Med 30: 1067-1074, 2013.

RYCHLI K, HUBER K, WOJTA J: Pigment epithelium-derived factor (PEDF) as a therapeutic target in cardiovascular disease. Expert Opin Ther Targets 13: 1295-1302, 2009.

SPURNÁ J, KARÁSEK D, KUBÍČKOVÁ V, GOLDMANNOVÁ D, KRYSTYNÍK O, SCHOVÁNEK J, ZADRAŽIL $\mathrm{J}$ : Relationship of selected adipokines with markers of vascular damage in patients with type 2 diabetes. Metab Syndr Relat Disord 16: 246-253, 2018.

TAHARA N, YAMAGISHI S, TAHARA A, NITTA Y, KODAMA N, MIZOGUCHI M, MOHAR D, ISHIBASHI M, HAYABUCHI N, IMAIZUMI T: Serum level of pigment epithelium-derived factor is a marker of atherosclerosis in humans. Atherosclerosis 219: 311-315, 2011.

TOMBRAN-TINK J, CHADER GG, JOHNSON LV: PEDF: a pigment epithelium-derived factor with potent neuronal differentiative activity. Exp Eye Res 53: 411-414, 1991.

UEDA S, YAMAGISHI S, MATSUI T, JINNOUCHI Y, IMAIZUMI T: Administration of pigment epithelium-derived factor inhibits left ventricular remodeling and improves cardiac function in rats with acute myocardial infarction. Am J Pathol 178: 591-598, 2011.

VILAHUR G, BEN-AICHA S, BADIMON L: New insights into the role of adipose tissue in thrombosis. Cardiovasc Res 113: 1046-1054, 2017.

WEI Y, LIU G, YANG J, ZHENG R, JIANG L, BAO P: The association between metabolic syndrome and vascular endothelial dysfunction in adolescents. Exp Ther Med 5: 1663-1666, 2013.

YAMAGISHI S, ADACHI H, ABE A, YASHIRO T, ENOMOTO M, FURUKI K, HINO A, JINNOUCHI Y, TAKENAKA K, MATSUI T, NAKAMURA K, IMAIZUMI T: Elevated serum levels of pigment epitheliumderived factor in the metabolic syndrome. J Clin Endocrinol Metab 91: 2447-2450, 2006.

YAMAGISHI S, MATSUI T, NAKAMURA K, TAKENAKA K: Administration of pigment epithelium-derived factor prolongs bleeding time by suppressing plasminogen activator inhibitor-1 activity and platelet aggregation in rats. Clin Exp Med 9: 73-76, 2009.

YAMAGISHI SI, MATSUI T: Anti-atherothrombogenic properties of PEDF. Curr Mol Med 10: 284-291, 2010.

YAMAGISHI SI, MATSUI T: Pigment epithelium-derived factor: a novel therapeutic target for cardiometabolic diseases and related complications. Curr Med Chem 25: 1480-1500, 2018.

YARMOLINSKY J, BORDIN BARBIERI N, WEINMANN T, ZIEGELMANN PK, DUNCAN BB, INÊS SCHMIDT M: Plasminogen activator inhibitor-1 and type 2 diabetes: a systematic review and meta-analysis of observational studies. Sci Rep 6: 17714, 2016. 
ZHANG H, WANG Z, FENG SJ, XU L, SHI HX, CHEN LL, YUAN GD, YAN W, ZHUANG W, ZHANG YQ, ZHANG ZM, DONG HY: PEDF improves cardiac function in rats with acute myocardial infarction via inhibiting vascular permeability and cardiomyocyte apoptosis. Int J Mol Sci 16: 5618-5634, 2015. 